IIIIIIIIIIIIII

Note

|IIIIIIIIIIIII

\section{Field survey of ryanodine receptor mutations (G4946E and I4790K) and their effects on biotic performance in the diamondback moth}

\author{
Megumi Fukada, Yuki Itagaki, \\ Atsuko Nagayoshi and Shoji SonOda* \\ School of Agriculture, Utsunomiya University, \\ Utsunomiya, Tochigi 321-8505, Japan
}

(Received February 11, 2019; Accepted April 1, 2020)

This study examined changes in the proportions of ryanodine receptor mutations (G4946E and I4790K) for Plutella xylostella populations in the field. Results show that the proportion of G4946E decreased during the survey years without diamide application and that insects with I4790K were observed less frequently during the survey period. This study also examined the biotic performances of diamide-resistant $P$. xylostella strains. The results show that the diamide-resistant strains exhibited hatchability, larval development, and fecundity equivalent to those of diamide-susceptible strains.

Keywords: cyantraniliprole, diamide, fitness cost, insecticide resistance, Plutella xylostella.

Electronic supplementary materials: The online version of this article contains supplementary material (Supplemental Table S1), which is available at http://www.jstage.jst.go.jp/browse/jpestics/.

\section{Introduction}

Plutella xylostella is a serious pest of cultivated Brassica worldwide. ${ }^{1)}$ Plutella xylostella has developed resistance to $95 \mathrm{com}-$ pounds including diamides (Arthropod Pesticide Resistance Database, https://www.pesticideresistance.org/). In Japan, resistance to flubendiamide and chlorantraniliprole in P. xylostella has been reported since the first confirmation of its occurrence in 2013..$^{2-5)}$ The amino acid mutation G4946E in the ryano-

\footnotetext{
* To whom correspondence should be addressed.

E-mail: sonodas@cc.utsunomiya-u.ac.jp

Published online April 23, 2020
}

(c) BY-NC-ND (c) Pesticide Science Society of Japan 2020. This is an open access article distributed under the Creative Commons AttributionNonCommercial-NoDerivatives 4.0 International (CC BY-NC-ND 4.0) License (https://creativecommons.org/licenses/by-nc-nd/4.0/) dine receptor is a major factor in target-insensitive resistance to flubendiamide and chlorantraniliprole in P. xylostella. ${ }^{6-9)}$ The involvement of metabolic detoxification enzymes in high-level diamide resistance has not been reported. ${ }^{10)}$

Cyantraniliprole, which was released to market in 2014, has been effective on P. xylostella strains showing resistance to flubendiamide and chlorantraniliprole. However, a strain showing high-level resistance to cyantraniliprole was established in the laboratory. ${ }^{11)}$ Our earlier report showed that the amino acid mutation $\mathrm{I} 4790 \mathrm{~K}$ is fundamentally responsible for the resistance to cyantraniliprole, as well as to flubendiamide and chlorantraniliprole. ${ }^{11)}$

Most insecticide resistance mechanisms, including those to diamides, are associated with fitness costs. ${ }^{12)}$ A chlorantraniliprole-resistant $P$. xylostella from Brazil showed reduced larval weight and fecundity. ${ }^{13)}$ In addition, a diamide-resistant $P . x y$ lostella strain with G4946E (Sudlon) showed a longer developmental period, reduced weight in immature stages except for the third instar, and reduced fecundity at $25^{\circ} \mathrm{C} .{ }^{12)} \mathrm{A}$ strain with cyantraniliprole resistance conferred by multiple genes showed reduced reproduction compared to reference strains without insecticide selection. ${ }^{14)}$ However, no data on biotic performances are available for a cyantraniliprole-resistant strain in which resistance is fundamentally conferred by $\mathrm{I} 4790 \mathrm{~K}$.

We examined seasonal proportion changes of G4946E in $P$. xylostella populations using quantitative sequencing (QS). ${ }^{15)}$ For this study, we first show the proportion changes in G4946E and I4790K in field populations under no selection with diamides, followed by cyantraniliprole application. Later, we examine biotic performances represented by hatchability, developmental period, and fecundity using diamide-resistant $P$. xylostella strains with either G4946E or I4790K.

\section{Materials and Methods}

1. Insects used for laboratory experiments

Diamide-susceptible NN67S and NN97S strains without G4946E and I4790K were obtained from Nihon Nohyaku Co., Ltd. The NN67S and NN97S strains were collected, respectively, in Kawachinagano city, Osaka prefecture, in 1967 and in Kishiwada city, Osaka prefecture, in 1997 to initiate laboratory cultures. Since then, they have been maintained without insecticide selections. The KU13 strain collected in Yamato town, Kumamoto prefecture, in 2013 was obtained from S. Higuchi (Kumamoto prefecture, Japan) in 2014. The KU13 strain with only G4946E exhibited high resistance ( $>10,000$ times that of the NN67S and NN97S strains) against flubendiamide and chlorantraniliprole. ${ }^{11)}$ The cyantraniliprole-resistant KA17 strain was established using insects collected from cabbage fields at the Kagawa Agricultural Experiment Station, Ayagawa town, Kagawa prefecture, on May 17, 2017, through selection with cyantraniliprole (10.3\% 
oil dispersion, Benevia; DuPont). ${ }^{11)}$ The KA17 strain with only I4790K showed high resistance $(>10,000$ times that of the NN67S and NN97S strains) to cyantraniliprole, chlorantraniliprole, and flubendiamide. ${ }^{11)}$ Insects of the NN67S, NN97S, and KU13 strains were maintained with radish (Raphanus sativus var. longipinnatus) seedlings at $25^{\circ} \mathrm{C}$ under a long photoperiod (16L:8D). For insects of the KA17 strain, young cabbage (Brassica oleracea var. capitate) or pak choi (Brassica rapa var. chinensis) leaves were used for propagation because the insects did not survive on radish seedlings.

\section{Insect collection in the field}

Plutella xylostella males were collected from cabbage fields (Site A and Site B) with the same area $\left(56 \mathrm{~m}^{2}\right)$ using pheromone-baited sticky traps (Sumitomo Chemical Co., Ltd.) set at the Kagawa Agricultural Experiment Station from March 15, 2017, through July 25,2019 . The traps, with a sticky paper plate and a white plastic roof, were set $50 \mathrm{~cm}$ above the ground, with a single trap per site. They were fundamentally replaced every 5 or 10 days (Table S1). Year-round cultivation of cabbages with almost identical planting schedules took place at both study sites. Site B was managed with no insecticide applications for pest control. At Site A, acetamiprid (20.0\% WDG, Mospilan; Nippon Soda Co., Ltd.) was applied on April 28, May 30, June 20, and July 25, 2017, and on May 14, May 28, and June 12, 2018. In 2019, cyantraniliprole was applied on April 5, June 10, and July 12 at Site A. The study sites were $c a .200 \mathrm{~m}$ away from each other.

\section{Estimation of G4946E and I4790K proportions}

After all adult males captured by the traps were removed from the sticky plates using $96 \% n$-hexane, they were used for genomic DNA extraction. Genomic DNA was extracted individually using a sample preparation reagent (PrepMan Ultra; Applied Biosystems). Briefly, a single insect was homogenized in $30 \mu \mathrm{L}$ of the reagent and was incubated at $95^{\circ} \mathrm{C}$ for $10 \mathrm{~min}$ with subsequent incubation at room temperature for $2 \mathrm{~min}$. After centrifugation at $15,000 \times g$ for $2 \mathrm{~min}$, the supernatant was recovered. An equal volume of genomic DNA $(1 \mu \mathrm{L})$ was mixed and $1 \mu \mathrm{L}$ of the resulting DNA mixture was used for the QS-based method described below.

The proportion of G4946E was estimated according to the QS-based method reported by Sonoda et al. ${ }^{16)}$ To establish the QS-based method for estimation of the proportion of I4790K, genomic DNA of resistant (KA17) and susceptible (NN67S) homozygotes for $\mathrm{I} 4790 \mathrm{~K}$ were mixed to produce the following molar ratios for standard DNA templates: $1: 9,1: 5,1: 2,1: 1$, $2: 1,5: 1$, and $9: 1$. The standard DNA templates were subjected to PCR amplification of the partial ryanodine receptor gene using primers $5^{\prime}$-tgtaaaacgacggccagtgaggcagcggtraagaagac- $3^{\prime}$ and $5^{\prime}$-cttcaaatggtagtacccgatc- $3^{\prime}$. In the former primer, the M13 -21 primer sequence was included in the $5^{\prime}$ end, as underlined. Quick Taq HS DyeMix (Toyobo Co., Ltd.) was used for PCR amplification. The PCR conditions were 1 cycle of $3 \mathrm{~min}$ at $94^{\circ} \mathrm{C}$; 40 cycles of $15 \mathrm{sec}$ at $94^{\circ} \mathrm{C}, 30 \mathrm{sec}$ at $60^{\circ} \mathrm{C}$, and $1 \mathrm{~min}$ at $72^{\circ} \mathrm{C}$; and finishing with a final extension of $72^{\circ} \mathrm{C}$ for $7 \mathrm{~min}$. Amplified DNA fragments were sequenced directly using the M13 -21 primer. The peak heights of nucleotides corresponding to I $4790 \mathrm{~K}$ on the sequence chromatogram were measured using software (PowerPoint 2016; Microsoft Corp.) to obtain the equation to estimate the proportion of $\mathrm{I} 4790 \mathrm{~K}$.

\section{Development and fecundity of $\mathrm{P}$. xylostella strains}

Four strains (NN67S, NN97S, KU13, and KA17) were examined for their hatchability, development, and fecundity. Eggs were collected from stock cultures of the respective strains. First instar larvae hatched from the eggs were introduced individually into plastic Petri dishes $(55 \mathrm{~mm}$ diameter $\times 17 \mathrm{~mm}$ height; AS One Corp.), each of which contained young pak choi leaves as a food source. Insect development was observed daily until adult emergence.

Fourth instar larvae of insect cultures were separated based on their gender identities before pupation and were allowed to emerge. Newly emerged adult females and males were paired. Then the respective pairs were introduced into plastic cylindrical containers $(15 \mathrm{~mL}$; AS One Corp.) with a piece of cabbage leaf $(10 \mathrm{~mm} \times 10 \mathrm{~mm})$. The eggs laid on the leaf were counted daily. The cabbage leaf piece was changed daily. Experiments to assess the biotic performances were conducted at $25^{\circ} \mathrm{C}$ under a long photoperiod (16L:8D). Dead adult males were replaced with living males. The significance of the differences between means was evaluated using Tukey's honestly significant difference (HSD) test.

\section{Results}

\section{Trap catches and seasonal proportion changes in G4946E and I4790K}

Trap catches and seasonal proportion changes in G4946E, including data reported by Itagaki and Sonoda, ${ }^{15)}$ are presented in Fig. 1 and Table S1. In general, trap catches were high in May-July. They decreased considerably in August at both sites in 2015-2018, as reported by Itagaki and Sonoda. ${ }^{15)}$ The decreased trap catches at both study sites persisted until the following spring, with the exception of a second small peak in trap catches in 2017 (Fig. 1).

In 2017, the proportion of G4946E increased from spring to summer and then decreased toward autumn at both study sites, as observed in 2015 and 2016 ${ }^{15)}$ (Fig. 1). At Site A, the increased proportion in 2017 under no diamide selection was less pronounced than in the prior two years under diamide selection. No noticeable increase in the G4946E proportion from spring to summer was observed in 2018 at either study site under no diamide selection. In 2019, the proportion of G4946E increased slightly from spring to summer at both study sites.

We tried to establish the QS-based method to estimate the proportion of I4790K. However, noticeable peak signals for the resistant nucleotide (adenine) were not detected for the standard DNA templates $1: 9,1: 5,1: 2$, and $2: 1$ (data not shown). Furthermore, the observed average signal ratio for $1: 1$ deviated 

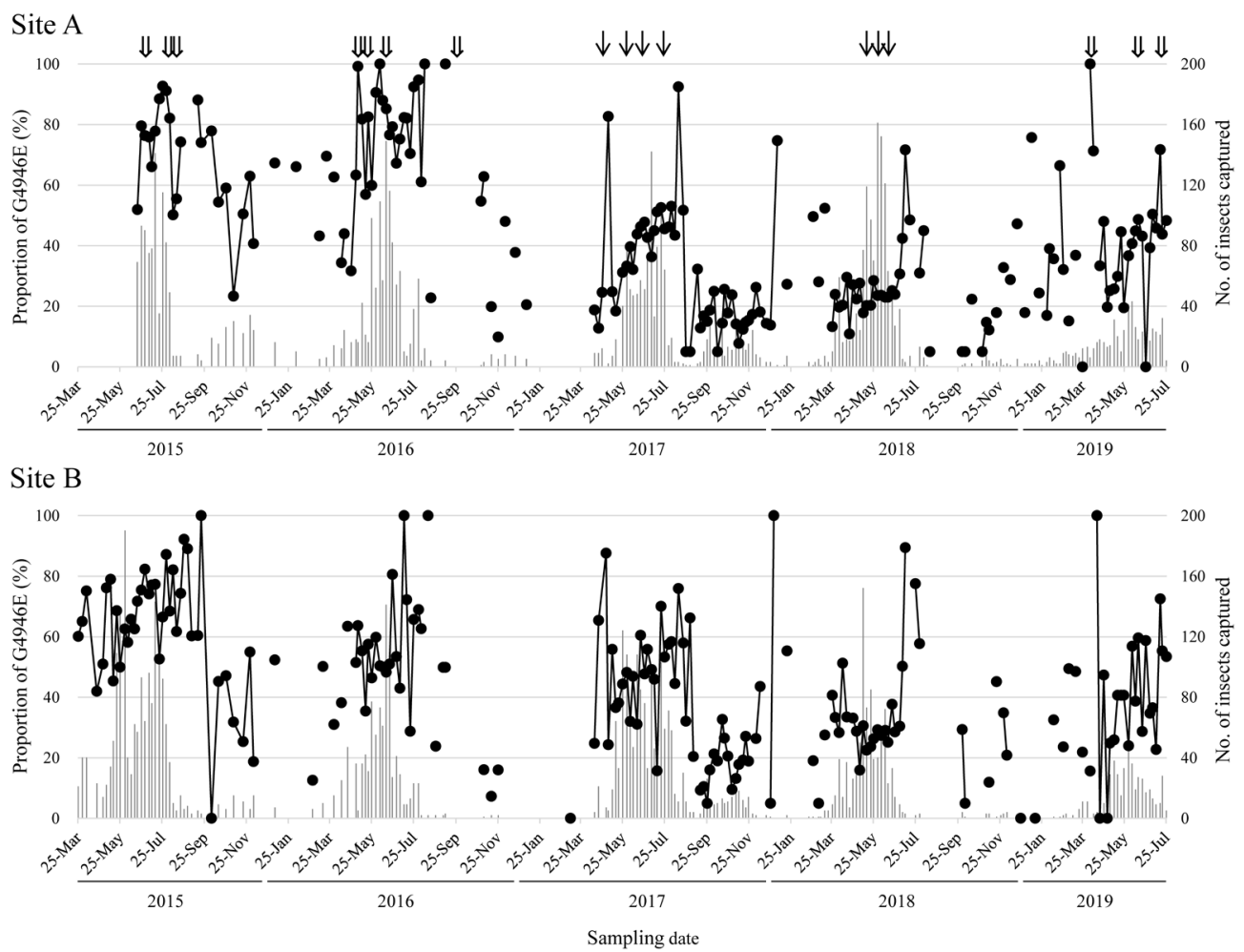

Fig. 1. Seasonal change in the proportion of G4946E in the ryanodine receptor gene in Plutella xylostella populations in cabbage fields with (Site A) and without (Site B) insecticide applications. Lines and dots show the proportion of G4946E (\%) in adult P. xylostella males captured by pheromone-baited sticky traps; bars show the number of adult $P$. xylostella males captured by the traps (trap catches). The population survey was administered from March 15, 2015, to July 25, 2019. Data from March 15, 2015 to March 15, 2017, were reported previously. ${ }^{15)}$ Details of the trap catches are available in Table S1. Double and single arrows respectively indicate diamide (flubendiamide or cyantraniliprole) and neonicotinoid (acetamiprid) applications.

greatly: 0.29:0.71 (data not shown). Therefore, for the I4790K site, the presence or absence of the resistant nucleotide in the DNA samples extracted from insects captured in 2017-2019 was examined on the sequencing chromatograms in this study. The resistant nucleotide for $14790 \mathrm{~K}$ was observed in samples collected on April 20, May 15, June 30, August 14, and November 30, 2017, and on July 2, July 31, October 15, and November 5, 2018, at Site A (data not shown). At Site B, the resistant nucleotide was observed on June 20, 2017, and on March 6, May 15, and November 5, 2018 (data not shown). In the samples, the proportion of $\mathrm{I} 4790 \mathrm{~K}$ was estimated to be less than $50 \%$ because the proportions of the resistant nucleotide were smaller than that observed in the standard DNA template 1:1 (data not shown).

\section{Hatchability and larval development of P. xylostella strains}

The NN67S, NN97S, KU13, and KA17 strains respectively showed hatchability of $89.5 \%(n=105), 90.1 \%(n=91), 83.3 \%$ $(n=90)$, and $91.7 \%(n=96)$. The larval development of the four P. xylostella strains is presented in Table 1. No noticeable difference in developmental periods was found between diamideresistant (KU13 and KA17) and -susceptible (NN67S and NN97S) strains (Table 1). Adult emergence of the four strains was $59.0-76.9 \%$ (Table 1). The shortest developmental period and the highest adult emergence were observed for the KU13 strain (Table 1).

Table 1. Development of four P. xylostella strains

\begin{tabular}{|c|c|c|c|c|c|c|c|c|}
\hline \multirow[b]{2}{*}{ Strain } & \multirow[b]{2}{*}{$n$} & \multicolumn{6}{|c|}{ Developmental period (day) } & \multirow{2}{*}{$\begin{array}{l}\text { Adult emer- } \\
\text { gence }(\%)^{a)}\end{array}$} \\
\hline & & $\begin{array}{l}\text { First instar larva } \\
\text { (mean } \pm \text { S.E. })\end{array}$ & $\begin{array}{c}\text { Second instar } \\
\text { larva (mean } \pm \text { S.E. })\end{array}$ & $\begin{array}{l}\text { Third instar larva } \\
\text { (mean } \pm \text { S.E.) }\end{array}$ & $\begin{array}{l}\text { Fourth instar larva } \\
\quad(\text { mean } \pm \text { S.E. })\end{array}$ & Pupa (mean \pm S.E.) & $\begin{array}{c}\text { First instar to } \\
\text { adult (mean } \pm \text { S.E.) }\end{array}$ & \\
\hline NN67S & 33 & $2.77 \pm 0.09 \mathrm{a}(33)$ & $1.59 \pm 0.19$ a $(29)$ & $1.91 \pm 0.09 \mathrm{a}(28)$ & $2.18 \pm 0.18$ a $(25)$ & $4.36 \pm 0.15$ a $(23)$ & $12.82 \pm 0.31 \mathrm{ab}(22)$ & 66.7 \\
\hline NN97S & 47 & $2.81 \pm 0.10 \mathrm{a}(47)$ & $1.58 \pm 0.12 \mathrm{a}(42)$ & $1.90 \pm 0.17 \mathrm{a}(41)$ & $2.68 \pm 0.14$ a (38) & $4.32 \pm 0.10 \mathrm{a}(35)$ & $13.29 \pm 0.26 \mathrm{ac}(31)$ & 66.0 \\
\hline KU13 & 39 & $2.20 \pm 0.07 \mathrm{~b}(39)$ & $1.63 \pm 0.09$ a $(35)$ & $1.60 \pm 0.15$ a $(33)$ & $2.33 \pm 0.19$ a $(32)$ & $4.63 \pm 0.10 \mathrm{a}(32)$ & $12.40 \pm 0.23 \mathrm{~b}(30)$ & 76.9 \\
\hline KA17 & 39 & $3.32 \pm 0.14$ c (39) & $2.05 \pm 0.14$ a (32) & $1.55 \pm 0.13 \mathrm{a}(28)$ & $2.50 \pm 0.13$ a (26) & $4.77 \pm 0.16$ a (25) & $14.18 \pm 0.23 c(22)$ & 59.0 \\
\hline
\end{tabular}

Numbers in parentheses show numbers of surviving insects. $n$ : Number of insects examined. Same letters indicate no significant difference (Tukey-HSD test, $p>0.05) .{ }^{a)}$ No. of adults emerged/no. of first instar larvae examined. 
Table 2. Longevity, total no. of eggs, and total no. of eggs per day of female adults of four P. xylostella strains

\begin{tabular}{lcccc}
\hline Strain & $n$ & Longevity (day) (mean \pm S.E.) & Total no. of eggs (mean \pm S.E.) & Total no. of eggs/day (mean \pm S.E.) \\
\hline NN67S & 15 & $4.2 \pm 0.24 \mathrm{a}$ & $102.8 \pm 7.29 \mathrm{a}$ & $24.8 \pm 1.5 \mathrm{a}$ \\
NN97S & 10 & $7.4 \pm 0.85 \mathrm{~b}$ & $109.7 \pm 11.36 \mathrm{a}$ & $15.8 \pm 1.4 \mathrm{~b}$ \\
KU13 & 11 & $7.3 \pm 0.62 \mathrm{~b}$ & $108.3 \pm 6.99 \mathrm{a}$ & $15.5 \pm 1.0 \mathrm{~b}$ \\
KA17 & 5 & $8.2 \pm 1.8 \mathrm{~b}$ & $126.2 \pm 25.17 \mathrm{a}$ & $16.6 \pm 4.2 \mathrm{~b}$ \\
\hline
\end{tabular}

Same letters indicate no significant difference (Tukey-HSD test, $p>0.05$ ).

3. Longevity and fecundity of female adults of $\mathrm{P}$. xylostella strains The longevity and fecundity of adult females of the four P. $x y$ lostella strains are presented in Table 2. The susceptible NN67S strain exhibited shorter longevity $(p<0.05)$. No difference in egg production was observed among the four strains $(p>0.05)$.

\section{Discussion}

Our earlier report described that the diamide resistance profiles of the KU13 and KA17 strains are fundamentally associated with G4946E and I4790K, respectively. ${ }^{11)}$ The proportions of G4946E decreased during the two years (2017-2018) without diamide selection at both study sites (Fig. 1). In fact, the proportion of G4946E from autumn in 2017 through spring in 2019 was substantially lower than $40 \%$, which is the threshold defining susceptibility of the population to flubendiamide. ${ }^{16)}$ These results suggest the fitness costs of G4946E and recovery of the susceptibility of $P$. xylostella populations that had once developed resistance to diamides (flubendiamide and chlorantraniliprole). The $\mathrm{LC}_{50}$ value of the KU13 strain with G4946E against cyantraniliprole was 680 times higher than that of the NN67S strain without G4946E but was below the agriculturally recommended concentration. ${ }^{11)}$ The slightly increased proportions of G4946E observed during spring-summer in 2019 under selection with cyantraniliprole may have been due to the partial involvement of G4946E in the cyantraniliprole resistance.

This study confirmed the presence of insects with $\mathrm{I} 4790 \mathrm{~K}$ at both study sites. However, their occurrence was not consistent in 2017 and 2018. Furthermore, no insect with I4790K was detected in 2019, even after cyantraniliprole applications at Site A. In contrast, the proportions of G4946E in P. xylostella populations in some prefectures in Japan were estimated to be greater than the threshold (40\%). ${ }^{15,16)}$ In fact, the detectable proportion of G4946E was found during the survey period at both study sites $^{15)}$ (Fig. 1). To further examine the fitness costs of G4946E and $\mathrm{I} 4790 \mathrm{~K}$, we examined the biotic performances of the KU13 and KA17 strains.

Earlier reports represented the fitness costs of diamide resistance as delayed development, reduced larval weight, and fecundity in P. xylostella. ${ }^{12-14)}$ However, the present study found no significant negative effect of diamide resistance conferred by I4790K or G4946E on hatchability, larval development, and fecundity at $25^{\circ} \mathrm{C}$, although adult emergence of the KA17 strain was the lowest among the four strains examined. Reportedly, temperature effects on the fitness of insecticide-resistant $P$. $x y$ lostella strains are higher at unfavorable low and high tempera- tures. ${ }^{12,17)}$ The fitness costs of diamide resistance conferred by G4946E and I4790K must be evaluated under different temperature conditions in the future.

The persistence of $P$. xylostella populations in winter depends more or less on the availability of Brassica plants, such as volunteer canola (Brassica napus L.) and wild turnips. ${ }^{18)}$ In this regard, the KA17 strain did not develop on the radish seedlings as described above. The possible narrower host range observed in the KA17 strain might adversely affect success in overwintering. The effects of host plants on the biotic performances of diamideresistant strains also remain to be examined in a future study.

Our results show that the cyantraniliprole-resistant KA17 strain exhibited hatchability, larval development, and fecundity equivalent to those in the susceptible strains, suggesting that insects with cyantraniliprole resistance might become prominent under certain optimal environmental conditions. Continuous proportion surveys of I4790K, in addition to G4946E, using field P. xylostella populations are expected to be valuable for developing optimal pest control strategies for lepidopteran pests, including P. xylostella.

\section{Acknowledgements}

This study was supported in part by Grants-in-Aid for Scientific Research (C) from the Japan Society for the Promotion of Science (JSPS) (No. 16K07624) and from the Ministry of Agriculture, Forestry and Fisheries, Japan, through the 'Genomics-based Technology for Agricultural Improvement; PRM01' research project. The authors thank M. Aizawa and S. Tsukuda (Kagawa prefecture, Japan) for insect collection.

\section{References}

1) N. S. Talekar and A. M. Shelton: Annu. Rev. Entomol. 38, 275-301 (1993).

2) T. Fukuda and S. Hayashikawa: Kyushu Pl. Prot. Res. 60, 75-78 (2014) (in Japanese with English summary).

3) K. Shimizu, T. Ootani, T. Kawana and M. Endou: Annu. Rep. KantoTosan Plant Protec. Soc. 61, 137-140 (2014) (in Japanese with English summary).

4) M. Inoue, K. Okabe and T. Ogawara: Annu. Rep. Kanto-Tosan Plant Protec. Soc. 62, 141-143 (2015) (in Japanese with English summary).

5) Y. Kunitomo and M. Kanaya: Annu. Rep. Kanto-Tosan Plant Protec. Soc. 63, 91-92 (2016) (in Japanese with English summary).

6) B. J. Troczka, A. J. Williams, M. S. Williamson, L. M. Field, P. Lümmen and T. G. E. Davies: Sci. Rep. 5, 14680 (2015).

7) B. Troczka, C. T. Zimmer, J. Elias, C. Schorn, C. Bass, T. G. Davis, L. M. Field, M. S. Williamson, R. Slater and R. Nauen: Insect Biochem. Mol. Biol. 42, 873-880 (2012).

8) L. Guo, Y. Wang, X. Zhou, Z. Li, S. Liu, L. Pei and X. Gao: Pest 
Manag. Sci. 70, 1083-1089 (2014).

9) D. Steinbach, O. Gutbrod, P. Lümmen, S. Matthiesen, C. Schorn and R. Nauen: Insect Biochem. Mol. Biol. 63, 14-22 (2015).

10) R. Nauen and D. Steinbach: "Advances in Insect Control and Resistance Management," eds. by A. R. Horowitz and I. Ishaaya, Springer International Publishing Switzerland, pp. 219-236, 2016.

11) A. Jouraku, S. Kuwazaki, K. Miyamoto, M. Uchiyama, T. Kurokawa, E. Mori, M. X. Mori, Y. Mori and S. Sonoda: Insect Biochem. Mol. Biol. 118, 103308 (2020).

12) D. Steinbach, G. Moritz and R. Nauen: Pest Manag. Sci. 73, 17891797 (2017).
13) L. M. S. Ribeiro, V. Wanderley-Teixeira, H. N. Ferreira, A. A. C. Teixeira and H. Á. A. Siqueira: Bull. Entomol. Res. 104, 88-96 (2014).

14) X. Liu, Y. Ning, H. Wang and K. Wang: Entomol. Exp. Appl. 157, 271278 (2015).

15) Y. Itagaki and S. Sonoda: J. Pestic. Sci. 42, 116-118 (2017).

16) S. Sonoda, K. Inukai, S. Kitabayashi, S. Kuwazaki and A. Jouraku: Appl. Entomol. Zool. 52, 353-357 (2017).

17) X. Li, M. A. Shuler and M. R. Berenbaum: Annu. Rev. Entomol. 52, 231-251 (2007).

18) H. Gu: Environ. Entomol. 38, 524-529 (2009). 